\title{
Planejamento Estratégico em Saúde: Uma Discussão da Abordagem de Mário Testa
}

\author{
Lígia Giovanella *
}

A partir de um estudo da produção teórica recente de Mário Testa (1983-7), é feita uma caracterizaçāo de sua proposta atual para o planejamento em saúde. Essa caracterização, porém, não leva à conformação de um método de planejamento, pois Testa propõe um modo de entender os problemas de saúde $e$ os processos de planejamento, apresentando apenas alguns elementos para esse processo. Ao compreender os problemas de saúde como socialmente determinados, Testa interessa-se pelo comportamento dos atores sociais, e pöe ênfase na análise das relações de Poder e na consideração das práticas de saúde, enquanto práticas ideológicas, conformadoras de seus sujeitos. Testa, assim, avança de uma proposta de planejamento estratégico em saúde para um pensar $a$ ação política em saúde. Poder e Ideologia são categorias que fundamentam esse pensar, sendo escolhidas para a análise de sua proposta. É realizado um estudo sobre Poder $e$ Ideologia, discutindo-se as compreensões de Testa a respeito. Dessa discussão, conclui-se que as práticas de saúde, enquanto práticas sociais, são práticas ideológicas $e$ afetam as concepçōes de mundo de seus sujeitos, sendo dificil, porém, garantir a direcionalidade da mudança dessas concepções.E argumenta-se favoravelmente ao conteúdo transformador da proposta de Testa para o planejamento em saúde, por desvendar os conteúdos de Poder nas açōes em saúde, não escamoteando as bases reais da dominaçâo, e por ser transparente nos deslocamentos de Poder que objetiva.

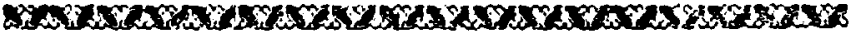

O enfoque estratégico de planejamento em saúde pode ser entendido como formulaçōes que rompem com a normatividade de um "deve ser" que se impõe sobre a realidade. Nestas, propõem-se processos de planejamento que objetivam alcançar o máximo de liberdade de ação a cada ação realizada. Para tanto, considera-se o problema do poder, admitindo-se o conflito entre

Cadernos de Saúde Pública, RJ, 6 (2) : 129-153, abr/jun, 1990
* Professora Assistente do Departamento de Administraçäo e Planejamento ENSP/Fiocruz.
Salide. 
forças sociais com diferentes interesses e com uma visão particular sobre a situação-problema na qual se planeja, fazendo parte do processo de planejamento a análise e a construção da viabilidade política.

Tendo essa compreensão, postulo a existência de três vertentes desse enfoque, elaboradas por autores latino-americanos: o "planejamento situacional", formulação de Carlos Matus para a planificação econômico-social global, que vem sendo adaptada para a saúde (Matus 1981, 1982-1987); a "proposta de Medellin", uma linha desenvolvida a partir de discussões promovidas pela OPAS e na Faculdade Nacional de Saúde Pública de Medellin, divulgada em documento da autoria de Juan José Barrenechea e Emiro Trujillo Uribe "STP 2000: Implicaciones para la Planificación y Administración de los Sistemas de Salud" (Barrenechea e Trujillo - 1987); e "as propostas programático-estratégicas" de Mário Testa.

Dessas vertentes, escolho a produção de Testa para estudo. Testa é ator importante do planejamento de saúde na América Latina: participa da elaboração e difusão do método Cendes/OPAS e, a partir da crítica a esse método e sua autocrítica, faz suas proposições. Como resultado de suas reflexōes, propōe para o planejamento de saúde "integrar o cálculo tradicional - referente ao diagnóstico e à proposta administrativa - com a análise estratégica da estrutura de poder setorial, e a análise das repercussōes das açōes propostas sobre esta estrutura, na tentativa de desenhar uma maneira de aproximar-se da posição de $\mathrm{Ha}$ bermas: criar uma estrutura comunicativa que devolva ao povo as ferramentas científicas necessárias para sua liberação" (Testa - 1986).

Testa não apresenta essa proposta ordenada em texto único. Para conhecê-la e discuti-la, inicialmente, realizei um estudo de sua produção recente (1983 1987), identificando os fundamentos e elementos de suas propostas programático-estratégicas.

\section{OS FUNDAMENTOS DA PROPOSTA DE MÁRIO TESTA}

Considero como fundamentos dessa proposição de Testa para o planejamento: sua compreensão do planejamento como prática histórica, o postulado de coerência que apresenta sua interpretação dos problemas de saúde enquanto problemas sociais e sua compreensão e análise do Poder, na sociedade e no setor (Testa, 1985 - 1986/1987).

Para Testa, o propósito do processo de planejamento em saúde é de mudança social. Pensar na transformação social significa pensar na construção de uma nova sociedade. Intervir na construção da história. 
Pensar o planejamento como prática histórica. Discute, então, as estratégias de transformação social historicamente gestadas, utilizando conceituação gramsciana. Considera que a análise desses processos históricos mostra uma combinação de estratégias de "ocupação de espaços" e de "enfrentamento" ("guerra de trincheiras" e "assalto ao poder").

O propósito de mudança determina um diferente método, pois considera o método necessariamente relacionado aos propósitos perseguidos. Método e propósitos, por sua vez, relacionam-se com a organização das instituições encarregadas de executar as ações pertinentes ao alcance dos propósitos. Postula, então, a existência de relações de determinação e condicionamento entre propósitos, método e organização. Relações essas que devem ser analisadas nas condições particulares de cada formação econômico-social, quando se discute um método de planejamento. Testa propõe um modo geral de análise dessas relações para sociedades capitalistas e dependentes, diferenciandoas dos países capitalistas desenvolvidos. São estas necessárias relaçōes entre propósitos, método e organização que Testa apresenta em seu "Postulado de Coerência" (Testa, 1987).

Testa entende saúde como "o jeito de andar a vida" e os problemas de saúde, tanto de situação de saúde como de organização setorial, como problemas sociais complexos nos quais intervêm inúmeras variáveis relacionadas de formas muitas vezes desconhecidas.

Considera que, para os problemas de situação de saúde, a análise que mais tem conseguido aproximar-se dessas complexas relações é a realizada pela epidemiologia social. Na epidemiologia social, o processo saúde-doença é entendido como expressão particular do processo social, sendo as desigualdades, no sofrer e adoecer entre grupos de pessoas, consideradas como decorrentes de diferenças de classe social.

Os problemas de organização setorial, representados, em grandes termos, pela alocação social de recursos para a atenção à saúde, são também problemas sociais. Fazem parte das questões relacionadas à reprodução da força de trabalho, e estão determinados economicamente por necessidades da acumulação e, politicamente, pelas lutas dos trabalhadores por sua condição de vida atual, e acerca do futuro ordenamento social (Testa, 1985).

No entender de Testa, proposiçōes em Saúde somente serão eficazes a longo prazo, quer dizer, levarão à resolução dos problemas de saúde, se fundamentadas na interpretação da determinação social do processo de produção desses problemas, pois esta interpretação é que mais dá conta da sua complexa determinação. 
Os problemas de saúde, enquanto problemas sociais, só podem ser resolvidos a partir do social mesmo. Pois a totalidade social nāo é divisível, não pode ser separada em partes. Nāo é possível modificar o social com propostas setoriais, diz Testa. As propostas setoriais podem, apenas, criar condiçōes que abram o caminho para a modificação do social (Testa, 1986).

Para mudar o social, é necessário pensar na questão do Poder, pois o Poder é categoria central na análise da dinâmica social. Significa pensar em como a forma de implementar uma ação de saúde - a estratégia - leva a alcançar um certo deslocamento de poder - uma política - favorável à resolução do problema. Assim, as estratégias em saúde extrapolam o setorial, abarcando o conjunto social, e dão eficácia às propostas a longo prazo. Para isso é necessário conhecer - Poder: o que é, suas determinações, suas relações, seus recursos, e encontrar formas para analisá-lo em sua distribuição setorial (Testa, 1986).

\section{A PROPOSTA}

Identificados esses fundamentos das suas proposições, seguindo a proposta de Testa para o planejamento de saúde inicialmente referida, podemos, assim, ordenar os conteúdos de seus trabalhos: o diagnóstico de saúde, constituído pelos diagnósticos administrativo, estratégico e ideológico e pela síntese diagnósti$\mathrm{ca} ; \mathrm{e}$ as suas propostas programático-estratégicas: a consideração dessas propostas, enquanto processos, pela análise de seus tempos técnicos e políticos, os programas de abertura, avanço e consolidação, e suas estratégias de formas organizativas, democráticas e participativas (Testa, 1986).

Através do diagnóstico, é feita a análise da realidade de saúde. Essa análise não é neutra e está determinada pelo propósito que se tenha. $O$ propósito, para Testa, é de transformação das relações do poder, através da realização de ações em saủde. Esse propósito produz um viês particular no diagnóstico: enfatiza-se a análise das relaçōes de Poder em Saúde.

Para um melhor conhecimento dos problemas de saúde, Testa propõe três tipos de diagnóstico: administrativo, estratégico e ideológico. O diagnóstico administrativo é parte da análise e cálculo tradicionais do planejamento de saúde. Através desse diagnóstico, população, doenças, mortes, recursos disponíveis e atividades realizadas em saúde são enumerados e quantificados. Cadeias epidemiológicas e nós técnicos críticos são identificados. A partir de critérios técnicos e de eficácia e eficiência, recursos e atividades necessários são calculados. 
O diagnóstico estratégico é a análise das relações de poder no setor. Neste diagnóstico, são identificadas e analisadas as desigualdades, na situação de saúde e na atenção à saúde, entre grupos sociais, determinadas por diferenças de classe social. Intemamente aos serviços, analisam-se as relaçōes de poder que aí ocorrem, e identifica-se a distribuição dos três tipos de poder em saúde: o técnico, o administrativo e o político. $\mathrm{Na}$ composição setorial analisa-se o poder administrativo concretizado pelo manejo de recursos e mediado pelo financiamento, diagnosticando os grupos sociais relacionados aos processo de financiamento.

O diagnóstico ideológico é o diagnóstico da ideologia dos grupos sociais com interesses em saúde. É - diagnóstico de suas compreensões sobre a saúde e a sociedade - consciência sanitária e social - e suas práticas correspondentes.

Após esse esmiuçamento da realidade, através dos três diagnósticos, é realizada a síntese diagnóstica: um momento integrador que reconstrói a realidade de saúde analisada. Através da síntese, identifica-se o espaço social setorial, enquanto sua estrutura de Poder. São identificados todos os atores e possíveis atores sociais de saúde e seus interesses, e analisadas sua força, suas relações e participação no debate da saúde.

A síntese diagnóstica é momento de início da formulação das propostas programático-estratégicas. Propostas cuja intenção é realizar açōes de saúde, objetivando mudanças. E pensadas desde a análise de sua viabilidade e de suas repercussões sobre a estrutura de poder na sociedade: as relações de poder entre os grupos sociais, dentro e fora do setor saúde. A ação em saúde é a parte programática da proposta. A estratégia é a forma de implementar essa ação, é o comportamerito dos atores, objetivando adquirir liberdade de ação para alcançar o objetivo buscado de transformação das relações de poder.

As propostas programático-estratégicas são pensadas enquantc processos que se realizam ao longo do tempo. Tempos técnicos e políticos, desencadeados pelas ações propostas, são avaliados.

Testa propōe três tipos de programas: de abertura, de avanço e de consolidação. A partir do diagnóstico, programas de avanço, contendo as mudanças consideradas necessárias, são elaborados. Com o intuito de criar viabilidade para as mudanças, através da construção de uma base social de apoio e pela negociação entre as forças sociais, programas de abertura são formulados. Pela institucionalização das mudanças e através da realizaçāo de medidas materiais que demonstrem concretamente a positividade das mudanças, estas 
são consolidadas adquirindo permanência. Estes são os programas de consolidação. O conjunto de programas, com suas formas organizativas correspondentes, conforma o processo de mudança.

As propostas programático-estratégicas objetivam acumular poder para os dominados e mudar as relações de poder, através da formação de uma consciência sanitária social e de classe. A implementação dos programas de avanço, através de formas organizativas das práticas propostas, democráticas e participativas, dão aos programas essa direcionalidade. Formas organizativas internas democráticas, com a criação de uma equipe de saúde solidária e colaborativa, são propostas como mecanismo para a construção da igualdade: a mudança das relações de poder. Formas organizativas internas democráticas são inseparáveis da abertura do setor saúde à participação direta da população. Esta é uma proposta de redistribuição de poder, objetivando constituir a população em ator social. A participação da população, através de suas organizaçōes, no debate de saúde, amplia esse debate e torna-a ator social em saúde.

Nesse ordenamento, como já disse, sigo a acima referida proposta de Testa para o Planejamento em Saúde. Em síntese, pode-se dizer que seu diagnóstico administrativo faz referência ao cálculo tradicional: contabilização e análise do rendimento dos recursos existentes, relação do contabilizado com um ótimo convertido em norma e cálculo dos recursos necessários para a execução das açōes propostas. Os diagnósticos ideológico e estratégico, juntamente com a síntese diagnóstica, põem ênfase na análise da estrutura de poder setorial. Os programas de abertura, avanço e consolidaçāo, elaborados a partir desta análise, consideram as repercussões das açōes propostas sobre essa estrutura de poder. As formas organizativas democráticas e participativas pretendem dar direcionalidade aos processos desencadeados, acumulando poder para as classes dominadas/subordinadas. Internamente aos serviços, alterando a distribuição de poder em seu favor, e externamente, através da mudança na consciência que podem provocar, influenciando na disputa de poder na sociedade e constituindo grupos de população como atores em saúde.

\section{DISCUSSĀO}

Mário Testa faz uma proposta acerca do planejamento de saúde, porém, não propõe um método de planejamento. Propóe um modo de entender o processo de planejamento e dá uma direcionalidade a esse processo, mas não instrumentaliza o processo. Não propõe um conjunto ordenado de procedimentos e técnicas 
de intervenção em complexas situações de conflito: um método de planejamento estratégico.

Considero que planejar em situações de conflito requereria uma série de técnicas e procedimentos que pudessem ser seguidos, seqüencialmente, ou realizados em momentos simultâneos e que dessem conta: da abordagem da complexidade social, em sua totalidade, expressada, com especificidade, em relação à saúde; da interação entre as diversas forças sociais; e da variabilidade e incerteza que significa tratar com o futuro, possibilitando a realização do "deve ser".

Ora, a realidade social não é regida por leis que se repetem. $\mathrm{Na}$ realidade social é possível, a partir de sua estruturação econômica, delinearem-se tendências: possibilidades com diferentes probabilidades para os acontecimentos. Tendências, mas não leis, porque há uma interação entre o econômico e o político. Porque uma suposta dinâmica social necessária, determinada objetivamente, a partir das relações econômicas atuais, é inseparável das iniciativas subjetivas das pessoas, das ações humanas livres (Konder, 1988). É inseparável da ação e luta de homens e mulheres reunidos segundo interesses comuns em classes/grupos sociais. A ação das classes/forças sociais em disputa e luta não pode ser previamente determinada pelo estabelecimento de leis. O resultado de enfrentamentos e alianças não é previsível. Querer fazê-lo significa instituir uma normatividade da política, uma normatividade pa$\mathrm{ra}$ as relações de poder.

"Tendência não é destino" (Ansoff, 1983). "As circunstâncias fazem os homens, assim como os homens fazem as circunstâncias" (Marx, 1986), e aí está a possibilidade do planejamento, possibilidade de imprimir direção à açã̃o futura, tanto maior quanto mais ampla, mais coletiva, a vontade da modificação. $O$ que năo é possível é dar conta de toda a complexidade que é a sociedade e o tratar com o futuro - principalmente em situaçōes de conflitos de vontades advindos de interesses antagônicos - através de uma série de técnicas e procedimentos. É possível, apenas, aproximar-se dessa complexidade, e Testa propõe alguns elementos para o planejamento em saúde.

Um dos principais elementos que Testa apresenta para um processo de planejamento é o diagnóstico. Nos diagnósticos propostos por Testa, são apresentadas algumas técnicas para cálculo de indicadores e análises de problemas, mas essas, no conjunto, não conformam um roteiro a ser seguido para a identificação e explicação dos problemas de saúde. Mais do que uma série de procedimentos, os diagnósticos constituem um quadro de análise para se pensarem os problemas de saúde, um modelo explicativo orientador

Cadernos de Saúde Pública, RJ, 6 (2) : 129-153, abr/jun, 1990 
do esmiuçamento da realidade, necessário para o levantamento e compreensão dos problemas de saúde.

Os programas de abertura, avanço e consolidação também não podem ser considerados, enquanto técnicas ou procedimentos, partes de um método, pois não contêm instrumental para a sua elaboração. Săo orientações para se pensarem processos de planejamento estratégico e não metodologia de elaboração de programas ou técnicas de análise de viabilidade: são orientaçōes para um pensamento estratégico.

A apresentação de três tipos de programas põe ênfase na necessidade da construção ativa da viabilidade e na importância da permanência da viabilidade para a consolidação das mudanças implementadas. Os programas de abertura põem ểnfase nas relações de poder, os de consolidação, na ideologia e os de avanço correspondem ao "deve ser". Programas de abertura e consolidação têm conteúdos diferentes, mas ambos referem-se à questão da base de apoio. Os de abertura, apoio para a decisão sobre o avanço, e os de consolidação, apoio para garantir a permanência do avanço. Em ambos, Testa afirma a importância do poder, enquanto ideologia nesse processo de mudança. E, por entender a ideologia como relação dialética entre saber e prática, Testa propõe formas organizativas democráticas e participativas que, no seu entender, contribuem para a formação de uma nova ética de solidariedade e transparência que oriente novas práticas sociais transformadoras, pois, ao compreender os problemas de saúde, enquanto determinados socialmente, e o setor como parte inseparável da totalidade social, para Testa, somente práticas sociais globais transformadoras poderăo levar a, e consolidar, mudanças em saúde.

Sua proposição deixa de ter, assim, uma especificidade setorial para tratar de influenciar na construção da história, imprimir direção aos processos sociais.

Pensar a ação de homens e mulheres na construção da história, na construção da realidade social, é pensar a ação política: pensar as relaçōes de poder na sociedade. Imprimir direção aos processos sociais é pensar na ampliação de uma vontade, tornando-a coletiva. Pensar uma vontade que é ação transformadora significa pensar a relação de Poder não apenas como repressão, mas também como Ideologia.

Este é o caminho de Testa e, por isso, avança de uma proposta de planejamento estratégico em saúde para um pensamento estratégico, um pensar a ação política em saúde. E, neste pensar a ação política, Poder e Ideologia são as categorias fundamentais e, por isso, as escolho para a análise que realizo de suas proposições.

Testa está interessado no comportamento dos atores sociais, pois é no comportamento dos atores que 
está a possibilidade de intervenção na construção da história direcionada à transformação das relaçōes de Poder na sociedade. Comportamento e consciểncia prática e concepção de mundo - são, para Testa, inseparáveis. Transformando-se as práticas, transforma-se a consciência, transformando-se a consciência, transformam-se os comportamentos, por isso, sua ênfase na consideração do Poder como Ideologia, e a importância dessas categorias para analisá-lo.

\section{PODER}

Para discutir o Poder em Testa, é necessário estudar o Poder. $\mathrm{Na}$ relação entre pessoas e coisas, ou coisas e coisas, o Poder tem um significado de capacidade que, aplicada sobre um objeto, produz um efeito nesse objeto, modifica esse objeto (Stoppino, 1986).

$\mathrm{Na}$ relação entre pessoas, uma a uma ou entre grupos, ainda de forma descritiva, o Poder não é uma capacidade que se detenha, é uma relação de comportamentos, onde o comportamento de uma pessoa ou grupo, de forma intencional e interessada, modifica o comportamento de outra pessoa ou grupo (Weber, 1974). E relação desigual, onde um é sujeito e outro objeto do Poder e que subentende sempre conflito.

Esta, porém, é apenas uma descrição da relação de Poder. É através da discussão da Política e do Estado que podemos aproximar-nos da essência do Poder, das suas reais determinações. Política pode ser considerada como tudo o que está relacionado com a distribuição, deslocamento ou conservação de Poder, e o Estado entendido como a maior organização política. Poder, Política e Estado muitas vezes confundemse. Bom exemplo dessa confusão, deste ser a mesma coisa, é quando considera-se a ciência política, por vezes, como a ciência do Poder, por vezes como a ciência do Estado.

Desde a origem do Estado Modemo, sua análise é inseparável da discussão do poder. O Estado é Poder absoluto, mantido pelo temor, em Maquiavel. EstadoLeviatã, em Hobbes: Poder imanente à natureza humana, que é cedido em contrato ao soberano, fundando - Estado, para garantir a propriedade e acabar com a guerra perraanente do "estado de natureza", pois "o homem é o lobo do homem". Estado: Poder absoluto e irresistível do soberano, garantido pela força.

Em Locke, o contrato funda o Estado e a sociedade. Estado que garante a propriedade, mas também a igualdade e a liberdade do "estado de natureza". Acordo garantido agora pelo consentimento. Homens livres que se acordam entre si e instituem um govemo legítimo. 
$\mathrm{Na}$ mesma linha de contrato entre homens livres e iguais, Rousseau: "Todos nascem livres e iguais $e$ sấo iguais perante a lei". A lei expressa a vontade geral. A vontade geral é soberana. O Poder funda-se na vontade geral, e o Estado representa a vontade geral (Chevallier, 1980).

Marx e Engels rompem com a teoria do Estado, do Poder fundado no contrato, deixando de lado o "deveria ser" e o "parece que é", ao analisarem as sociedades capitalistas européias de sua época. $\mathrm{Na}$ análise histórica da sociedade e do Estado realizada por Marx e Engels, o Estado é produto da divisão da sociedade em classes, e resulta de um processo através do qual a classe economicamente dominante torna-se politicamente dominante afirmando seu Poder sobre a sociedade inteira. Poder organizado de uma classe para a opressão de outra, que garante a reprodução da divisão da sociedade em classes. A sociedade que analisam Marx e Engels não é um imaginário estado de natureza, onde todos seriam, intrinsecamente, bons ou maus, mas a sociedade de seu tempo, onde a igualdade e a liberdade preconizadas pelos liberais burgueses são a liberdade do cidadão, nāo mais servo em vender a sua força de trabalho, e a livre concorrência no mercado; igualdade entre trabalhadores livres e capitalistas, quando se encontram no mercado trabalhadores que vendem a sua força de trabalho e proprietários dos meios de produção que a compram e os expropriam da riqueza que produzem. É sociedade dividida em classes, onde o Estado é poder organizado de uma classe para opressão de outra. Estado de interesses particulares de uma classe, e não da vontade geral (Marx e Engels, 1975), (Gruppi, 1986). E, reforça Lenin, todo o Estado é ditadura de classe: órgão de opressão de uma classe sobre outra (Lenin, 1974).

$E$ na análise marxista que encontramos, então, a determinação fundamental do Poder: o Estado nasce com as classes e com a luta de classes. Não estamos mais frente a justificativas do Poder, mas, sim, frente aos fundamentos do Poder: a divisão da sociedade em classes. Divisão da sociedade, em classes, pela apropriação privada dos meios de produção. Classes definidas pelos diferentes lugares ocupados pelas pessoas nas relações de produção.

Considerar apenas esta determinação econômica significa, para Carlos Nelson Coutinho, ter uma compreensão restrita sobre o Estado. Esta compreensão que, enquanto conhecimento, situa-se no nível de abstração do modo de produção, onde contrapõem-se bipolarmente duas classes fundamentais, diz ele, deve ser articulada com as determinações mais concretas que resultam da análise de cada formação econômicosocial atual, cada vez mais complexas. Deste modo, 
amplia-se o conceito de Estado e aproxima-se mais de sua realidade concreta, síntese de múltiplas determinaçōes, introduzndo-se novas determinaçōes “... não apenas na esfera econômica (articulação hierarquizada de diferentes modos de produção) e na social (complexificação da estrutura e dos conflitos de classe), mas também na esfera do político (novas caracteristicas do fenômeno estatal e maior especificação de seu papel na reprodução global da sociedade" (Coutinho, 1987).

A sociedade e o Estado tornam-se mais complexos. Mais complexas, também, tornam-se as análises marxistas sobre o Estado e o Poder. Gramsci trata de um período histórico onde já ocorreu uma maior socialização da política, os direitos políticos estão mais desenvolvidos, e é na Política a sua ênfase. Socialização da política que amplia o Estado, fazendo-o avançar sobre a sociedade civil, e que é presença das massas na política, pré-condição para sua autonomia (Coutinho, 1987).

Em Gramsci, o Poder de Estado é Poder de classe, mas não se mantém apenas pela violência, mantém-se também pela Ideologia. Gramsci nos mostra a ampliação do Estado, juntando nele Sociedade Política e Sociedade Civil, repressão e ideologia, domínio e direção, coerção e hegemonia.

Em Gramsci, é Poder ainda de classe, fundado na relação de produção, mas que se mantém não mais apenas pela coerção. A dominação mantém-se pela aceitação por parte dos dominados de uma concepção de mundo que pertence aos seus dominadores. Visão do mundo da classe dominante que se transforma em senso comum, em filosofia das massas, que aceitam a moral, os costumes e o comportamento institucionalizado da sociedade em que vivem. O Estado promove esse conceito único de realidade, impedindo o desenvolvimento da consciência da classe trabalhadora, ampliando o seu papel na perpetuação das classes (Coutinho, 1981, Gramsci, 1980).

Gramsci retoma os conteúdos sobre o Estado dos escritos de Marx e Engels e avança, encontrando as bases materiais da ideologia no interior da sociedade civil, num conjunto de organizações privadas que conformam a mediação necessária entre a infra-estrutura econômica e o Estado-coerção, a Sociedade Política. Aparelhos privados de hegemonia - escola, partidos, sindicatos, associaçōes, toda organização material da cultura e meios de comunicação - portadores materiais de diferentes visōes de mundo, diferentes valores em disputa.

Gramsci, preocupado em como as classes dominantes capitalistas, a despeito da atuação de organizações operárias revolucionárias, conseguem ter a aceitação de grandes parcelas das classes trabalhadoras, e

Cadernos de Saúde Pública, RJ, 6 (2) : 129-153, abr/jun, 1990 
tentando entender esse consentimento, encontra, portanto, suas bases na concepção de mundo, no sistema de crenças e valores morais, nas raízes culturais. Encontra a base da aceitação no controle sobre o pensamento, sobre a consciência das pessoas, controle que se exerce em todos os lugares, năo só nos, mas através dos aparelhos de Estado.

Poulantzas, constatando o avanço nas sociedades contemporâneas do que denomina de "Estatismo Autoritário" - o avanço cada vez maior do Estado em todos os setores da vida social nos países capitalistas, e do autoritarismo e burocratismo nos países de socialismo real - preocupa-se em estudar e esclarecer as bases dessa situação para que, compreendidas e identificadas as estruturas que devem ser transformadas, seja possível traçar trajetórias para um socialismo democrático (Poulantzas, 1985).

Em Poulantzas o fundamento do Estado (nāo a origem) está lá onde está a relação de produção. A base material do Poder está na relação de produção e na divisão social do trabalho. $\mathrm{Na}$ relação de produção, fundam-se as classes e suas lutas: as relações de Poder. O Estado funda-se nas lutas e é condensação material de uma relação de forças entre classes dominantes - o bloco no poder. Relações entre os integrantes deste bloco e as classes dominadas. Lutas que perpassam o Estado. Relação de forças que adquire materialidade nos aparelhos/instituiçōes do Estado, conformando um conjunto contraditório e fissurado. Classes dominadas inscritas na materialidade institucional do Estado como focos de oposição. Em Poulantzas as lutas populares inscrevem-se na própria materialidade da sociedade política.

Estado não acima das classes, mas com uma autonomia relativa, frente ao bloco no poder, que lhe permite a organização deste bloco e do consenso das classes dominadas em relação às dominantes.

Foucault estuda a "Microfísica do Poder". Não mais o que é o Poder e suas determinaçōes, mas os dispositivos de exercício do Poder, a tecnologia através da qual obtém-se a sujeição: mecanismos de Poder que controlam o corpo minuciosamente: gestos, atitudes, discursos. Rede de dispositivos de Poder à qual ninguém escapa.

Não existe Poder fora de seu exercício, afirma Foucault, pois, Poder não é coisa que se possua: não se possui Poder - exerce-se Poder. O Poder em Foucault é também relação: relação Poder-Resistência. Relações de Poder que incidem sobre os corpos, tornando-os úteis: corpo produtivo e submisso, dócil e lucrativo. Relações de Poder presentes em toda parte. Exereício de micropoderes em redes mais ou menos hierárquicas, onde cada um é centro de transmissão de Poder. 
Poder que se exerce através de mecanismos disciplinares. Tecnologia de controle sobre os corpos que reparte, fixa e distribui espacialmente os indivíduos, classifica-os, tira deles o máximo do tempo e o máximo de forças, treina os corpos e codifica os comportamentos. Mantém os corpos sob visibilidade plena, vigilância contínua e permanente, e constitui um aparelho completo de observações e registros, produzindo um saber.

Dispositivos de Poder que tornam o seu exercício mais rápido e útil: gasto mínimo e eficiência máxima. Mecanismos do exercício cotidiano e físico de micropoderes: relações inigualitárias e assimétricas.

O Poder é também positivo no sentido produtivo. Ele năo é só negativo: pune, recalca, reprime, pelo esquadrinhamento disciplinar adestra o corpo, produz 0 indivíduo (Foucault, 1977, 1982).

Conciuindo, podemos dizer que o Poder é relação social que, na sociedade dividida em classes, tem os seus fundamentos nas relaçōes de produção e na divisão social do trabalho. Exerce-se na sociedade política/ aparelhos de Estado e na sociedade civil/aparelhos privados de hegemonia, conformando um Estado ampliado, resultado da condensação material de uma relação de forças entre classes e fraçōes de classes.

Poder sustentado pela repressão e pelo consentimento, pela coerção e pela persuasão. Repressão que suplicia os corpos, sempre pronta para ser deflagrada. Consentimento alcançado pela difusão de uma concepção de mundo, de valores morais, normas de conduta, ascendência intelectual. Consentimento alcançado através do controle sobre o pensamento e o controle e adestramento dos corpos, através das disciplinas.

O Poder é relação, é luta. Poder macroexercido nas relaçōes entre classes e frações, entre grupos sociais: luta de classes. Poder microexercido nas relações entre as pesscas, nos processos de trabalho, em todas as atividades humanas. Exercício de micropoderes que controla, adestra, pune. Relação de controle e sujeição, mas sempre luta: Poder-Resistência.

O Poder social não é só Poder fundado na divisão da sociedade em classes - nas relaçōes de produção e na divisão social do trabalho - não é só Poder de Estado, mas articula-se sempre ao Estado.

Poder é, entāo, relação sempre desigual, presente em todas as relações sociais. Relação de forças que possui bases materiais. Controle sobre os corpos, controle sobre a consciência.

Temos que tomar cuidado para que, na tentativa de encontrarmos as múltiplas determinaçōes, não caiamos novamente na causa única: poder econômico de classe. Grande tentação, sem dúvida, as relações de Poder fundam-se nas relaçōes de produção e na divisão

Cadernos de Saúde Pública, RJ, 6 (2) : 129-153, abr/jun, 1990 
social do trabalho, mas são, ao mesmo tempo, relações instituídas em todos os âmbitos da vida social, sustentadas por inúmeros mecanismos.

No capitalismo, o Poder Social funda-se nas relações de produção, mas sustenta-se de inúmeras e variadas maneiras, nāo estando nem personificado em poucos indivíduos, nem materializado apenas nos aparelhos de Estado. É relação desigual que se sustenta pela repressão, pelo consentimento, pela persuasão, por valores morais e raízes culturais, normas de conduta, pela organização material da cultura, pelos meios de comunicação de massa, pelo carisma, através da crença, do afeto, pela lei, saber, conhecimento científi$\mathrm{co}$, pela competência funcional da autoridade, pelas disciplinas (o adestramento e controle dos corpos), por medidas materiais positivas às classes trabalhadoras, pela ampliação de direitos sociais.

Não vamos também reconstruir um novo Leviatã: o monstro Poder, presente em toda a parte. Essas são formas de sustentação e, ao mesmo tempo, lugares/ espaços de oposição, pois, Poder é sempre relação, é sempre luta. Ali onde está o Poder está a Resistência: subordinação-insubordinação, sujeição-rebeldia, repressão-subversão. Do mesmo modo, não há um determinismo econômico inelutável, no qual se funda o Poder. As relaçōes de produção e a divisão social do trabalho determinam Poder e, ao mesmo tempo, fundam a contradição que produz o conflito, luta: vontade de transformar essas relaçôes.

Através desse processo de pesquisa e aprendizagem que buscou conhecer o que é o Poder, suas determinaçōes e formas de exercício, com o intuito de discutir as noções de Poder que fundamentam as proposiçōes de Mario Testa para a ação em saúde, encontrei grande parte dos autores que informam as reflexōes de Testa.

Posso dizer, assim, que, mais que discutir as noções de Poder em Testa, acabo por fundamentá-las, o que, sem dúvida, também é uma forma de discussão.

Em Mário Testa, o Poder é uma categoria explicativa da realidade, e o seu pensamento estratégico objetiva afetar as relaçōes de Poder. De forma abstrata, diz Testa: Poder é capacidade possuída por alguém, pessoa, ou grupo. É capacidade de um indivíduo lograr que outro faça algo que este não faria, se aquele não tivesse poder. Submetido às suas múltiplas determinações, Poder é a capacidade de uma classe social realizar seus objetivos históricos. (Testa, 1981)

Testa aceita o conceito de Poder-relação mas torna sempre a reafirmar o Poder como capacidade que se possui. $\mathrm{Na}$ literatura consultada, há também uma grande confusão entre considerar o Poder como capacidade e como relação. Poulantzas, às vezes, refere-se 
ao Poder como uma capacidade e Foucault, por vezes, institui um Senhor-Poder afastando-se da relação.

O Poder só existe em exercício e nāo é separável da relação. $O$ Poder não pode ser considerado como na teoria da soma-zero, onde o que um ganha de Poder o outro perde, pois não tem substância própria. A relação de poder, a relação política, é uma relação produtiva cujo resultado é algo novo, diferente dos interesses estritos de cada participante.

Mario Testa, no seu diagnóstico estratégico, tenta encontrar formas precisas de quantificar o Poder, elaborando indicadores de Poder. Por não poder ser considerado como tendo substância própria, separável da relação, é que é tão difícil, para não dizer impossível, a construção de indicadores de poder.

Mas o Poder en Testa não é só capacidade, é também relação que constrói a sociedade e é indissoluvelmente ligado ao Estado. Testa discute o Estado em vários momentos de seu trabalho e de várias formas. Apresenta-o como monopólio do uso legítimo da força física (Weber). Discute a concepção marxista estrita de Estado, em contraposição a uma teoria liberal do Estado, afirmando-o enquanto Estado de classe que mantém a desigualdade. Refere-se também à teoria relacional do Poder de Poulantzas (Testa, 1986).

Setorialmente o Poder é tipificado por Testa em técnico, administrativo e político. Capacidades em relação a: informações, recursos e mobilização de grupos sociais; formas de análise e estudo desses tipos de poder são apresentadas; propõe o conhecimento da distribuição do Poder técnico pela análise dos grupos sociais que manejam cada tipo de informação em cada espaço; a aproximação à distribuição do Poder administrativo é feita através da análise dos grupos sociais relacionados às várias fases do financiamento, pois considera o dinheiro como equivalente universal a todos recursos. Para a análise do Poder Político, diz Testa, esse deve ser considerado enquanto ideologia (Testa, 1987-1).

Em variada literatura, e no senso comum, o Poder enquanto capacidade é tipificado das mais variadas formas - econômico, administrativo, aquisitivo, marítímo, médico, ideológico etc, - o que sugere a pertinência de uma tipificação. Como vimos, porém, o poder nāo é capacidade que se detenha, é sempre relação.

Poder-Capacidade é relação pessoa-coisa, pessoaobjeto. A relação pessoa-coisa na relação de Poder é a relação com recursos para o exercício do Poder. Poderíamos, então, considerar, por exemplo, os conhecimentos e os variados recursos utilizados na organização e administração dos serviços de saúde, mediados pelos recursos financeiros, como recursos do exercício do Poder. E mais correto, portanto, quando Testa afir- 
ma serem estes tipos de Poder referidos a diferentes espaços, do que a diferentes capacidades, ao qual poderemos agregar formas de exercício de Poder com diferentes conteúdos, em cujo exercício são utilizados diferentes recursos.

Quanto ao Poder-Técnico, o conhecimento não só determina um espaço de exercício do Poder, como também, freqüentemente, justifica o exercício dessa relação desigual. O Poder-Técnico é fundamentado na relação Poder-Saber. Em Foucault, todo saber tem sua gênese numa relação de Poder, e todo saber assegura o exercício de um Poder. O saber só é saber dotado de Poder: saber é verdade, e verdade é Poder (Foucault, 1982). Em Poulantzas, a relação Poder-Saber funda-se na divisåo entre trabalho manual e trabalho intelectual, sendo o Estado capitalista o lugar onde a relação orgânica entre Saber e Poder, trabalho intelectual e dominação política, efetua-se de maneira mais acabada. O Estado capitalista cristaliza o trabalho intelectual através da sua organização burocrática, diz ele. A relação Saber-Poder expressa-se, também, muito claramente, na relação médico-paciente, onde o médico, em nome de um Saber, tem o Poder e o direito legal de manipular, física e moralmente, $o$ doente.

Essa relação entre Poder e Saber é tão forte que Foucault afirma ser impossível separar o saber do Poder, e, nas análises e propostas de tendências marxistas, o saber - o conhecimento sobre a realidade, o intelectual, a vanguarda, consciência, a verdade - contém a potencialidade da transformação social. Testa tem, portanto, toda razão ao referir-se a um Poder técnico em exercício no espaço social da saúde.

A tipificação de um poder administrativo tem como pressuposto um "poder econômico", onde o dinheiro é equivalente universal. Recursos financeiros, porém, năo podem ser mecanicamente considerados como equivalentes de todos os recursos, de todas as capacidades. Uma capacidade administrativa não compreende apenas uma disponibilidade de recursos financeiros, mas, também, a organização e gestão dos chamados "recursos-humanos", a força de trabalho - habilidades adquiridas que transcendem, sem dúvida, à questão financeira. Esses outros recursos são capacidades que só podem ser colocadas em ação a partir da disponibilidade dos recursos financeiros, mas que nāo se confundem com estes.

Considerar o poder político como uma capacidade é uma questão mais complicada. Considerar o Poder Político como capacidade, detida por uma pessoa ou grupo social, de desencadear uma mobilizaçẫo - capacidade de manejo de interesses - coloca as pessoas mobilizadas como coisas manipuladas, o que não é admissível quando a proposta é de criação de uma 
sociedade solidária e transparente: verdadeira sociedade democrática. Mário Testa, porém, ao considerar - Poder político enquanto ideologia, supera essa definição de capacidade, adquirindo grande importância as concepções de Gramsci para sua análise. O Poder Político, em seu exercício, é relação e não mais capacidade que se detém.

Mesmo com essas objeçōes, considero, portanto, que essa tipificação para o exercício do Poder no setor saúde proposta por Testa tem um valor analítico, ao ajudar a identificar a disponibilidade de certos recursos de exercício do Poder, por parte de cada um dos atores sociais em disputa no debate sobre saúde, e ao identificar cenários/espaços onde se exerce o Poder.

$O$ poder é ainda analisado por Testa, quanto aos resultados de seu exercício. Diz ele que, em relação aos resultados do exercício do Poder, existe um Poder cotidiano e um Poder societário, um implicando o outro. Um poder cotidiano que se refere ao que fazer e como fazer, a cada dia, e que implica a construção da sociedade futura, o Poder societário, estabelecendo-se, assim, dentro das instituições, a relação entre o fazer de cada dia, e a construçăo da história (Testa, 1987).

Sua proposição de formas organizativas democráticas e participativas decorre da compreensão dessa relação entre Poder Cotidiano e Poder Societário, pois uma sociedade verdadeiramente democrática constróise no ato de fazer de cada dia. Diz Mário Testa que, na situação de desigualdade em que vivemos, a prática democrática é mecanismo para construçáo da igualdade desejada.

Vimos, assim, que a análise do Poder, em Testa, é informada por concepções de diversos autores. A noção do poder que orienta suas proposições tem elementos dos micropoderes de Foucault: micropoderes que se exercem nos 'como fazeres' e 'que fazeres' de cada dia; da teoria relacional do Poder, em Poulantzas: o espaço social global é o conjunto dos campos de força gerados pelas relações entre os atores sociais, em debate a cada momento; e da concepção de Gramsci: sujeitos sociais tornados atores sociais pela sua participação no Estado, nos organismos da Sociedade Civil e/ou da Sociedade Política, e pela ênfase dada à consideraçăo do Poder como Ideologia.

\section{IDEOLOGIA}

Mário Testa apresenta o que entende por Ideologia em vários momentos e com diferentes nuances. Em geral, uma compreensảo de Ideologia inclui um saber e uma prática: um saber que é uma concepção 
da realidade e uma prática que constrói os seus sujeitos (Testa, 1987).

Diz Testa que Ideololgia geralmente é entendida, apenas, como sistema de idéias, no sentido de uma concepção de mundo, mas que, mesmo não explicitamente definido como tal, esse sistema é também norma de conduta. E que, nos Estados complexos, pela mudança do caráter desses Estados, Ideologia é a forma em que todas as práticas sociais, ao mesmo tempo que realizam uma produção específica de seus 'que fazeres', constroem os sujeitos que delas participam (Testa, 1986).

O sujeito social forma-se quando da realização de seu trabalho abstrato, pela sua situação na relação de produção, mas o processo de ideologização - processo que consolida ou transforma a consciência/concepção de mundo/uma ética/conjunto de valores ocorre em todas as práticas sociais perpassadas pelas relaçōes de Poder, principalmente através das formas organizativas dessas práticas, as formas organizativas das relaçōes de Poder, diz Testa.

Para discutir essa concepção de Ideologia, em Testa, é preciso conhecer como outros autores entendem Ideologia, e desvendar um pouco (pelo menos) - complexo processo de formação de uma concepção de mundo e de produção da tomada de consciência.

Ideologia, em sua concepção moderna, é um termo utilizado com diferentes significados. Em 1801, teve um sentido primeiro na acepção literal da palavra: "ciência das idéias". Destutt de Tracy - um dos ideólogos, "grupo de sábios" que, em 1795, pós-revolução francesa, fora encarregado de fundar um centro do pensamento revolucionário no "Institut de France" -, em seu "Elementos de Ideologia", pretendeu elaborar uma ciência da gênese das idéias: uma história natural, onde as idéias exprimiam a relação do corpo humano, enquanto organismo vivo, e o meio ambiente (Hall, 1983).

Desse primeiro sentido, Ideologia, atualmente, apresenta uma ampla gama de significados. $O$ mais comum e difundido é de um sistema de idéias, ora com sentido de visão de mundo, ora com sentido de crenças políticas. Nesse último significado, é conjunto de idéias em relação ao sistema social que visa a orientar os comportamentos políticos coletivos. "Sistemas de idéias conexas com a ação" (que compreende) "um programa e uma estratégia para a atuaçâo" e "objetivam defender ou mudar a ordem política existente" (Bobbio et all, 1986).

Outro significado de Ideologia é o de pré-noções, pré-científico, idéias vulgares contrapostas ao que é científico. Esta é a noção em Dürkheim. Segundo esse autor, ideologia é todo conhecimento não-objetivo da 
realidade, isto é, toda forma de conhecimento onde não ocorre a separaçāo entre o sujeito do conhecimento e o objeto do conhecimento. No entender de Dürkheim, para estudar a sociedade, o indivíduc deve encará-la como não fazendo parte dela (Hall, 1982). Foucault, por sua vez, opõe-se completamente a essa idéia. Para ele, nem a ciência é um conhecimento produzido por um sujeito que supera as suas condiçōes particulares de existência e coloca-se na posição de neutralidade objetiva do universal; nem a Ideologia é um conhecimento onde o sujeito tem a sua relação com a verdade perturbada pela sua condição de existência. Como vimos, Foucault mostra que as relações de Poder constituem o saber, não existindo sober neutro: "todo saber é político" (Foucault, 1982).

Outras vezes, Ideologia constitui-se da totalidade das formas de consciência social em referência às superestruturas ideológicas. Outras vezes, ainda, Ideologia é considerada como o conjunto de idéias políticas relacionado aos interesses de uma classe.

Diferente dos significados anteriores é o que considera a Ideologia como o pensamento teórico que pretende desenvolver-se sobre seus próprios princípios abstratos, mas que, na verdade, é a expressão da realidade econômica e social, que não é considerada determinante deste pensamento. Nesse sentido, Ideologia é forma invertida do pensamento sobre a realidade social, que nasce das contradiçöes sociais e as oculta. Nessa acepção, considera-se que as representações que os homens fazem da situação social são determinadas pelo processo real da sua vida, mas, como nas sociedades capitalistas os processos e produtos resultantes da ação dos homens são dele alienados, aparecem como independentes da sua ação, o mesmo ocorrendo com as idéias, aparecendo como autônomas e separadas da realidade social concreta, representando-a falsamente. Esse último significado de Ideologia é o empregado por Marx e Engels em sua crítica aos neo-hegelianos alemães, em texto de 1845-6 intitulado "Ideologia Alemä" (Marx e Engels, 1986).

A compreensão de Ideologia, em Testa, é diferente da de Marx na Ideologia Alemā. Em Marx, Ideologia é compreensão invertida da realidade que nasce das contradições sociais e oculta estas contradições, objetivando manter a dominação: idéias da classe dominante tomadas como universais. Testa não nega a existência de uma Ideologia dominante, mas argumenta que, na sociedade de Estado complexo, o processo de ideologização dá-se nas condições do acordo de classes que é o Estado, tornando-se a Ideologia dominante năo mais Ideologia de uma só classe. Ëm Testa Ideologia não é, necessariamente, inversão da realidade, nem se contrapōe ou é critério de Verdade. 
Mas há também semelhanças. A concepção de Ideologia, em Testa, aproxima-se do conceito de Ideologia de Marx, ao afirmar a base material de produção das idéias e distancia-se, ao não conceber Testa a Ideologia como inversão da realidade. Aproxima-se, ainda, pois o conceito de Ideologia, em Marx, também sugere o conteúdo de um saber e uma prática, pois é um conjunto de interpretações (uma concepção de mundo), acompanhado de normas e regras sociais (normas de conduta, formas de agir).

Com Lenin, há uma ampliação do significado de Ideologia. Numa situação de confronto de classes, diz ele, a Ideologia aparece ligada aos interesses da classe dominante e a crítica a essa Ideologia ligada aos interesses das classes dominadas (Bottomore, 1988). A Ideologia adquire, então, um novo conteúdo: idéias/ consciếncia política, ligadas aos interesses de cada classe, concepção esta compartilhada por Testa.

Em Gramsci, Ideologia tem um primeiro significado de sistema de idéias orgânico: superestrutura necessária a determinada estrutura. No bloco histórico, diz ele, as forças materiais são o conteúdo e as ideologias, a forma. Distinção meramente didática, afirma, pois não se podem conceber historicamente forças materiais sem forma, e as ideologias seriam apenas caprichos pessoais, sem as formas materiais (Gramsci, 1972).

Em Gramsci, Ideologia não significa falsa consciência em contraposição a uma consciência verdadeira. Em Gramsci, todo conhecimento tem um conteúdo ideológico e toda a concepção de mundo orienta a prática dos homens. Consciência/concepção de mundo e prática política são, para ele, inseparáveis. Ideologia em Gramsci tem, assim, um sentido geral de "unidade entre uma concepção do mundo e uma norma de conduta adequada a ela"(Coutinho, 1981). Concepção de mundo que transcende o mero conhecimento, articulando-se diretamente com a prática. A conceituação de Testa de Ideologia é próxima, portanto, à concepção gramsciana. As duas compreendem um conhecimento e uma prática. Em ambos, um saber que é uma concepção de mundo inseparável da prática. Em Testa, uma prática cuja forma em que se realiza constrói seus sujeitos, quer dizer, uma prática cujo conteúdo ideológico encontra-se nas suas formas organizativas e que se transforma ao construir a consciência de seus sujeitos.

A concepção de Ideologia em Testa é, portanto, próxima da de Gramsci, porém não está claro ainda como se forma e se muda uma concepção de mundo. Essa compreensão é necessária para poder discutir com Testa sua consideração de que são as formas organizativas, como se realizam as práticas, que constroem a consciência de seus sujeitos. 
Bourdieu afirma e demonstra, através de suas investigações, que a transformação do sistema de valores culturais (incluída aí a concepção de mundo) é, ao mesmo tempo, conseqüência e condição das transformaçōes econômicas, mas não reflexo imediato dessas transformaçōes (Bourdieu, 1979).

Bourdieu comprova que a consciência é determinada pelas condiçōes materiais de existência. Porém, essa relação não é mecânica, é mediada por um "sistema de disposiçōes", uma maneira de ser e representaçōes geradas pelas experiências vividas. Sistema inscrito, por sua vez, na sua condição objetiva de existência.

Bourdieu relaciona a consciência com a condição material de existência, e mostra o campo e as condições de desenvolvimento de uma consciência revolucionária - os trabalhadores permanentes submetidos ao cálculo e à previsibilidade - mas não diz por que, entre integrantes de uma mesma classe, compartilhando semelhantes condiçōes de existência, uns adquirem uma consciência objetiva dessa situação e participam da construção de um projeto coletivo de transformação social, e outros não.

Indica-nos que, através de todas as práticas realizadas e experiências vividas, os sujeitos sociais constroem sua concepção de mundo que, por sua vez, impulsiona suas práticas - o que fundamenta positivamente as proposiçōes de Testa - mas não discute quais são os tipos de práticas que têm potencial transformador da concepção de mundo. Questão fundamental na discussão de Testa.

Em Lukács, as práticas consideradas como potencial transformador da consciência são práticas de participação na luta coletiva por interesses econômicos coletivos, e pela ação educativa do partido revolucionário, organização construída a partir dessa consciência. Essas práticas constroem uma concepção de mundo que inclui a "consciência de classe para si", a partir de um processo de reflexão de cada pessoa sobre essas suas experiências (Lukács, 1977).

Gramsci dá grande importância à formação das concepçōes de mundo, pois encontra, aí, as bases para o consentimento e aceitação da dominação por grandes parcelas da classe trabalhadora, sendo a arena da luta pela consciência, para ele, arena fundamental da luta política.

Em Gramsci, as práticas com potencialidade transformadora das concepções de mundo são ampliadas e não se dão mais, como em Lukács, apenas no âmbito da luta reivindicatória e da ação do partido. Essas práticas estendem-se para o amplo terreno dos aparelhos privados de hegemonia: todas as organizaçōes políticas da sociedade civil (partidos, sindicatos, asso-

Cadernos de Saúde Pública, RJ, 6 (2) : 129-153, abr/jun, 1990 
ciaçōes), os meios de comunicação e toda a organização material da cultura, incluída aí a escola. Em Gramsci, cada um é um pouco filósofo, é portador de uma concepção de mundo e pode, portanto, contribuir na formaçẩo de novas maneiras de pensar (Gramsci, 1982). Toda pessoa exerce alguma atividade intelectual, e é impossível separar o homo sapiens do homo faber, ou produzir um gorila amestrado, como queria Taylor, diz Gramsci. A transformação da concepção de mundo está, então, na possibilidade de elaboração de maneira crítica da atividade intelectual que cada um exerce. Através da elaboração crítica do conteúdo intelectual do trabalho de cada um, formam-se intelectuais orgânicos que dão homogeneidade e consciência à classe trabalhadora. Esses intelectuais, por sua vez, impulsionam a transformação da consciência pela promoção da discussão das práticas de trabalho de cada um, fazendo com que essas práticas tornem-se - fundamento de uma nova e integral concepção de mundo.

Encontramos, aqui, a base gramsciana da proposição de Mário Testa de formas organizativas democráticas e participativas para o trabalho em saúde. Testa propõe a formação de uma equipe de saúde organizada democraticamente, que discuta suas práticas e decisões, e a abertura das instituições de saúde à participação das organizações populares, para a discussão das práticas aí realizadas, objetivando a transformação das concepçöes de mundo desses sujeitos. Testa, portanto, propōe o mesmo que Gramsci: um trabalho consciente, que tome a prática de trabalho de cada um base de uma nova concepção de mundo, cimento da hegemonia da classe trabalhadora.

Isso não significa, porém, que tenhamos esgotado a discussão da formação e transformação das concepções de mundo. Abordar essa questão exaustivamente significaria, ainda, pelo menos, conhecer como tem sido tratada no estudo da formaçāo das representaçōes, através da linguagem no processo de comunicação, na semiologia, no estudo dos processos educativos, na discussão sobre a socialização, na psicologia social. Essas possibilidades de ampliação do campo de estudo mostram bem a complexidade dessa discussão e indicam a existência de inúmeras mediações entre a consciência e a condição de existência.

Se podemos, portanto, concordar que a pertinência de classe, pelo lugar ocupado na produçāo, estrutura possibilidades de concepções de mundo, possibilitando uma certa forma de socialização e acesso a diferentes compreensões de realidade, não podemos entender essa determinação, mecanicamente, pois isso seria linearizar o complexo processo que é a produção da formação de uma concepção de mundo. Processo frag- 
mentário, que compreende rupturas, originalidade e criatividade da sistematização de cada pessoa.

O que, sem dúvida, podemos concluir desse estudo parcial é que a formação de uma concepção de mundo é um longo processo de elaboração das experiências pessoais que têm sua base material na condição de existência, condição esta entendida não apenas como constituída pelo seu processo de produção material, mas pelo conjunto das relaçōes sociais vividas por cada um. E que, nesse complexo processo, difícil de apreender, de formação e transformação das concepções de mundo, as formas organizativas democráticas e participativas são práticas que afetam a concepção de mundo de seus sujeitos e podem contribuir para a transformação dessas concepções de mundo, e impulsionar novas práticas, pela elaboração crítica dos, conteúdos das práticas realizadas que possibilitam. É impossivel, porém, afirmar em que medida isso ocorre.

Mário Testa, ao propor formas organizativas democráticas e participativas - visando a construção de um nova ética, de solidariedade e transparência -, está propondo a formação de sujeitos sociais democráticos imbuídos de uma nova ética integrante de sua própria personalidade, transformada, portanto, em força material. Testa sugere, assim, que a construção de uma sociedade realmente não-autoritária (um socialismo democrático) está na possibilidade da formação de sujeitos sociais conscientes não-autoritários e autônomos que direcionem suas práticas a esta construção. A construçāo da sociedade democrática está na possibilidade de transformação dos sujeitos sociais pelo estabelecimento de novas relações, e pela sua participação em práticas sociais diferenciadas.

Argumentamos, assim, favoravelmente ao conteúdo transformador da proposta de Testa para o planejamento e a ação em saúde. Podemos concluir que a proposição de estabelecimento de novas formas organizativas das práticas tende a mudar a relação de poder exercida naquela prática e a transformar as concepçōes de mundo de seus sujeitos, contribuindo para uma mudança nas relaçōes de força, pela potencialidade de realização de novas práticas coletivas impulsionadas por essa nova concepção de mundo. E que a proposta de Mário Testa para o planejamento de saúde tem uma potencialidade intrínseca transformadora, ao desvendar os conteúdos de Poder nas ações em saúde, não escamoteando as bases reais da dominação, e por ser transparente em seus próprios conteúdos de Poder: explícita nos deslocamentos de poder que objetiva. 
This article characterizes Mario Testa's propositions regarding health planning, on the basis of his recent theorethical analysis. The characterization doesn't imply the construction of a planning method, as Testa only presents some elements for the understanding of health problems and planning processes. Testa consideres health problems as socially determined, and therefore he emphasizes the analysis of social actor behaviour, power relationships and health practices taken as ideological practices giving orientation to actors. Testa goes beyond the strategical health planning proposition and proposes a reflection on political action in health.

Testa's thinking is based on such categories as power and ideology. This article discusses how he understands these categories. This discussion concludes that health practices are social practices and also are ideological practices influencing actor's view so, it is difficult to know how these world's views are going to change, Testa's propositions are inovating within the field of health planning, as they show that health actions have a power basis.

The theses of Mario Testa regarding health planning are defended in light of their potential to transform reality, by revealing the role of social power in health related actions, and rendering explicit objectives regarding power relationships.

\section{REFERÊNCIAS BIBLIOGRÁFICAS}

ANSOFF, H. Igor. Administração Estratégica. São Paulo, Ed. Atlas, 1983.

BARRENECHEA, Juan Jose \& TRUJILLO URIBE, Emiro. Salud para Todos en el año 2.000. Implicaciones para la Planificación y Administración de los Sistemas de Salud. Medellin, Un. Antioquia/OPS/OMS, 1987.

BOBBIO, N; MATTEUCCI, N. \& PASQUINO, G. Dicionário de Polftica. 2.* ed. Brasília, Ed. UNB, 1986.

BOURDIEU, Pierre. O Desencantamento do Mundo. São Paulo, Ed. Perspectiva, 1979.

BOTTOMORE, T. (ed.). Dicionário do Pensamento Marxista, Rio de Janeiro, Zahar, 1988.

CHEVA LLIER, Jean-Jacques. As grandes obras polticas de Maquiavel a nossos dias. 3: ed, Rio de Janeiro. Agir Ed. 1980.

COUTINHO, Carlos Nelson. Gramsci, Porto Alegre, L. \& PM, 1981. - Dualidade de poderes. 2! ed. Săo Paulo, Ed. Brasiliense, 1987.

Cadernos de Saúde Pública, RJ, 6 (2) : 129-153, abr/jun, 1990 
FOUCAULT, Michel, Vigiar e Punir. Petropolis, Vozes, 1977.

- Microfisica do Poder. Trad. Org. Roberto Machado. 3: ed. Rio de Janeiro, Ed. Graal, 1982.

GRAMSCI, Antonio. Introducción a la Filosofia de la Praxis. 2: ed. Barcelona, Ed. Barcelona, Ed. Península, 1972.

- Maquiavel, a Polftica e o Estado Moderno. 4: ed. Rio de Janeiro, Civilizaçăo Brasileira, 1980.

- Os Intelectuais e a Organização da Cultura. 4." ed. Rio de Janeiro, Civilização Brasileira, 1982.

GRUPPI, Luciano. Tudo começou com Maquiavel. 7: ed. Porto Alegre, L. \& PM., 1986.

HALL, Stuart. Interior da Ciência: Ideologia e a Sociologia do Conhecimento. In: Centre for Contemporary Cultural Studies - Univ. Birminghan, Da Ideologia. 2: ed. Rio de Janeiro, Zahar, 1983. p. 15-44.

KONDER, Leandro. O destino e o Marxismo, in O Destino, Rio de Janeiro, 1988.

LENIN. O Estado e a Revolução. Porto, Graf. Firmeza, 1974.

LUKÅCS, Gyōrgi. Historia y Consciencia de Clase. Barcelona, Grijalbo, 1977.

MARX, Karl \& ENGELS, Friedrich. Manifesto do Partido Comunista. Lisboa, Ed. Avante, 1975.

- A Ideologia Alemã (Feurbach). 5! ed. São Paulo, Hucitec, 1986.

MATUS, Carlos. Planificación, Libertad y Conflicto. Cuadernos de IVEPLAN N: 1, Caracas, 1981.

- Politica y Plan. Caracas, Ed. Iveplan, 1982. 1987.

POULANTZAS, Nicos. O Estado, o Poder e o Socialismo. 2: ed. Rio de Janeiro, Graal, 1985.

TESTA, Mario. Planificación Estratégica en el Sector Salud. Caracas. CENDES/UCV. 1981. Mimeo.

- - Pensar en Salud. Buenos Aires, 1983-6. Mimeo.

Pensamiento Estratégico, Lógica de Programación, Estrategia y Programación. Buenos Aires, 1986. Mimeo.

- Estrategia, Coherencia y Poder en las Propuestas de Salud - Parte I. Cuademos Médico Sociales. Rosario (38) 4: 24, 1987.

- Estrategia, Coherencia y Poder en las Propuestas de Salud - Parte II. Cuadernos Médico Sociales. Rosario (39)3: 28, 1987.

WEBER, Max. Economia y Sociedad. México, Fondo de Cultura Económica, 1974. 